sala preta

ppgac

\title{
Ensaiadores na cena brasileira dos séculos XIX e $x x$
}

\section{Theatrical regisseurs in the Brazilian scene in the 19th and 20th centuries}

\section{Elizabeth R. Azevedo}

Elizabeth R. Azevedo

Professora do Departamento de Artes cênicas e do PPGAD da ECA-USP

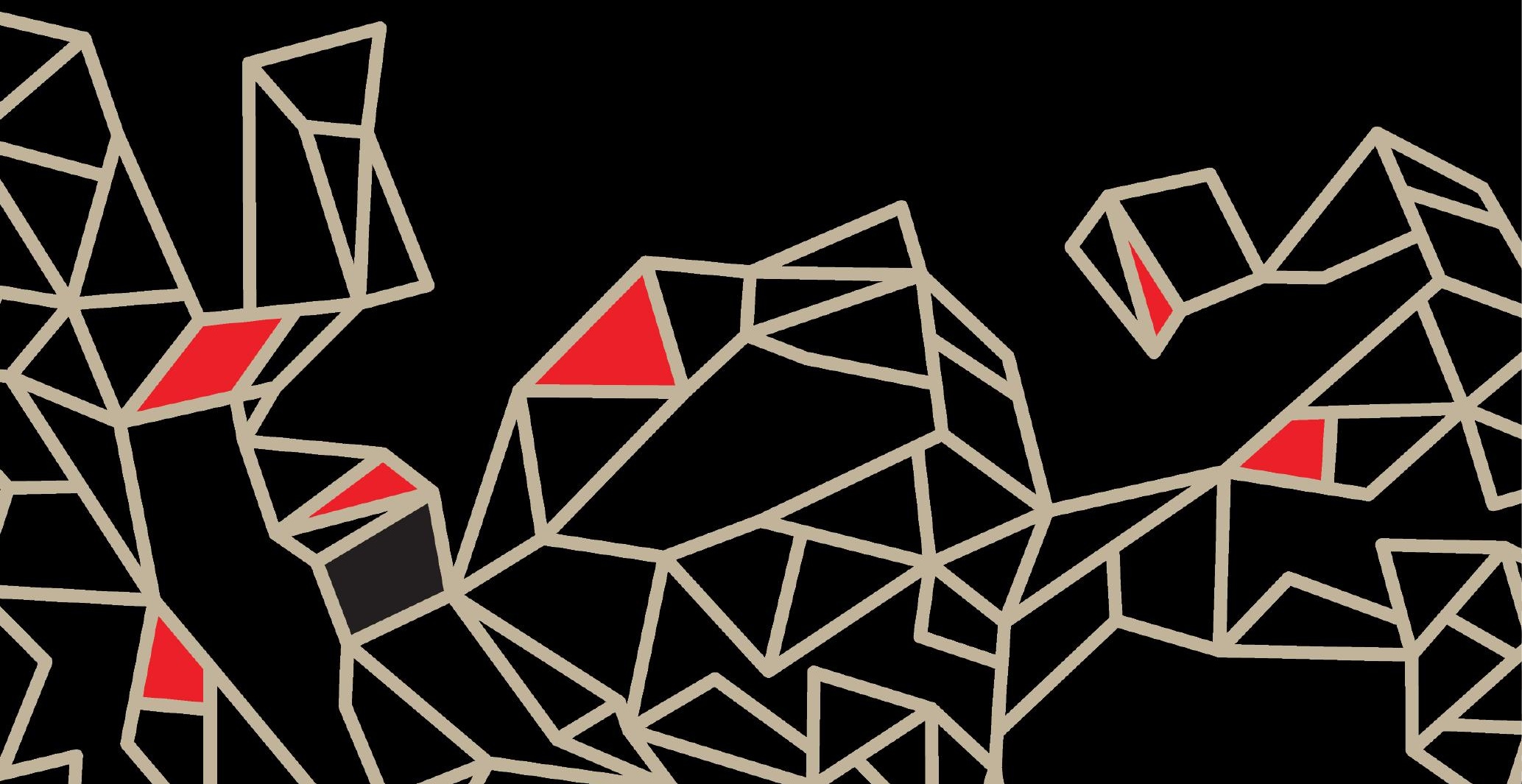




\section{Resumo}

O artigo procura refletir, ainda que rapidamente, sobre a importância do estudo das atividades dos ensaiadores do teatro brasileiro do século XIX, procurando apresentar a trajetória de três profissionais que estiveram presentes nos palcos nacionais: Emile Doux, Enrico Cuneo e Eduardo Victorino.

Palavras-chave: Ensaiador, Emile Doux, Enrico Cuneo, Eduardo Victorino.

\section{Abstract}

This paper discuss, if only briefly, the importance of studying the activities of the regisseurs of the Brazilian theater of the nineteenth century, trying to present the trajectory of three professionals who attended the national stage: Emile Doux, Enrico Cuneo and Eduardo Victorino.

Keywords: Regisseurs, Emile Doux, Enrico Cuneo, Eduardo Victorino.

A figura do ensaiador tem passado ao largo da maioria das pesquisas sobre o teatro brasileiro do século xIx e início do xx. Vistos em geral como meros marcadores de posição de atores no palco, ou "fiscais de trânsito", como sugeriu o crítico Clóvis Garcia ${ }^{1}$, na verdade, suas funções poderiam se estender para além dessa mera indicação. O depoimento de Clóvis Garcia se colocava em um momento no qual o teatro brasileiro tentava superar as práticas da cena consagradas há décadas, talvez séculos, e valorizar, principalmente, a função do diretor teatral, o que fazia que se desprestigiasse o papel dos ensaiadores que ainda se mantinham em atividades nos anos 1940.

No entanto, mais do que um opositor ao ensaiador, o moderno diretor teatral poderia ser visto como herdeiro do desdobramento e da valorização de algumas práticas já presentes nas funções do ensaiador e que acabaram

1. Porque "eles apenas marcavam a posição dos atores: 'vai para lá', 'vem para a esquerda', 'vai para a direita"'. Depoimento sobre o tema da modernização do teatro brasileiro (COSTA, 2008, p. 54) 
por se destacar e ganhar autonomia ${ }^{2}$. O ensaiador teria sido o precursor do moderno diretor teatral.

É fato que o ensaiador se incluía em um sistema bem acabado e muito eficiente do fazer teatral que garantiu durante gerações a sobrevivência de companhias, atores e do teatro enquanto atividade cultural. Tal sistema comportava basicamente a fixação de gêneros e subgêneros dramáticos, fosse do teatro dramático ou musical, bem como a padronização de uma tipologia limitada de personagens masculinos e femininos ${ }^{3}$.

Em um antigo registro existente sobre o teatro no Brasil, por exemplo, a presença do ensaiador já é mencionada. Athos Damascno apresentou um contrato datado de 1797 no qual a atriz Maria Benedita Queirós Montenegro, que entre outras obrigações e direitos, se compromete a ser

[...] obrigada a contentar-se com aquele vestuário tal qual lhe der o dono da casa; e a sujeitar-se com tudo a boa ou má direção do ensaiador e vontade do empresário; será obrigada a se apresentar pronta de todo o vestuário nas óperas de meio caráter e entremezes [...]. (DAMASCENO, 1956, p. 4)

Vê-se aí, além de um claro tom impositivo, a perspectiva de um juízo de valor do trabalho do ensaiador, que poderia ser de "boa" ou "má" qualidade. Deduz-se também que atores e atrizes, não raramente, entravam em conflito com os mesmos ${ }^{4}$.

Segundo o professor Walter Lima Torres Neto, que comparou as funções do ensaiador com aquelas do diretor teatral e do encenador contemporâneo, o ensaiador era quem transpunha o texto, composto dentro de uma convenção bem conhecida e sempre reproduzida, para o palco, garantindo o respeito

2. O moderno diretor, tanto como o ensaiador, se preocupava em valorizar e dar vida a obra de autor dramático. O que mudou não foi tanto a tarefa, mas o tipo de dramaturgia, que já não se pautava mais pelas convenções de gêneros e tipos consagrados.

3. Como gêneros, podemos lembrar: drama, comédia, opereta, revista, mágica etc. Dos tipos estabelecidos de personagens tínhamos: a ingênua, a dama galante, o galã, o centro nobre, o baixo cômico e vários outros. Lembre-se ainda que o valor dos contratos feitos com os atores se estabelecia a partir do tipo que ele representava. Todo esse sistema codificado e "fechado" condicionava inclusive a dramaturgia que era composta em função da existência de atores especializados.

4. Importante seria encontrar os contratos que tenham sido firmados com os próprios ensaiadores e estudar quais as atribuições a eles destinadas. 
à reprodução cênica de uma determinada realidade, cuidando de cenários, figurinos, iluminação etc.. O ensaiador não produziria

[...] um pensamento conceitual sobre a cena que ele administra e agencia; seu trabalho prima pela adequação da execução de uma escrita cênica codificada. [...] O ensaiador é o executor do texto teatral. [Já o diretor teatral seria] o prático de uma cena que busca a melhor tradução da palavra do autor, interpretando-a, normalmente servindo-a como seu portavoz [...] sobretudo atribuindo sentido e concretude cênica segundo uma interpretação específica. [Mais contemporaneamente, o encenador] é ele que assina de fato a autoria daquilo que o espectador vê [...] é o pesquisador e reorganizador de discurso oriundo de um universo fabular ficcional não necessariamente dramático. (TORRES NETO, 2001b, p. 273-274)

Torres Neto reconhece a presença do ensaiador em época muito anterior ao exemplar nacional ${ }^{5}$. Fala de sua presença já nas primeiras montagens do século xv na Itália, quando da construção e utilização dos novos espaços teatrais permanentes.

Entendemos então que, o legado que constitui o conjunto de técnicas e procedimentos de trabalho atribuídos ao ensaiador remontaria ao Renascimento. Desde o surgimento da perspectiva linear; o acabamento da caixa de ilusão da cena frontal com sua moldura e o arco do proscênio; e, a fixação de um repertório de gêneros claramente definidos herdeiro do século xvII pode-se identificar a trajetória desse perfil. Mesmo consciente do problema desta periodização acerca dessas faixas temporais, procuramos localizar o ensaiador nessa extensão temporal devido ao fato de que enquanto o tempo avançava, após a saída da Idade Média, sua função ora era desempenhada por um músico; um cenógrafo; um ator; um autor e, somente na segunda metade do século XIX é que temos notícia de que ele se dedica exclusivamente à representação. (TORRES NETO, 2001b, p. 273-274, grifo meu)

Vê-se que a função de alguém com autoridade para organizar os diversos elementos componentes da cena passou a se firmar ao longo do tempo com a crescente construção de novas salas de espetáculo e a consolidação do sistema de tipificação e especialização dos atores nos chamados emplois.

5. Nós poderíamos também voltar às primeiras manifestações registradas do teatro nacional, com as montagens de José de Anchieta, nas quais se acredita que o autor se incumbiu também da organização da encenação. 
No século xIX, sobretudo depois de 1850, caracterizou-se um excepcional crescimento e mercantilização do teatro, espalhando-se cada vez mais pelos continentes, criando grandes empresários especializados nessas turnês, transformando o mundo em uma verdadeira sociedade do espetáculo, como a apresentam os trabalhos de Charles Christopher e de Christopher Balme. Nesse sistema, a presença do ensaiador se tornou cada vez mais necessária e especializada.

O século xIX é o momento culminante de seu trabalho visto a proliferação de teatros e o crescimento de uma demanda de entretenimento nas principais cidades europeias e americanas. Quando eclode o advento do naturalismo no teatro é o ensaiador teatral o homem de confiança de diversos autores dramáticos que com suas peças querem chamar atenção para os novos fundamentos de uma arte que busca refletir o real de forma precisa, expondo a miséria dos ambientes e das personagens, rompendo de uma vez por todas com a idealização do comportamento ficcional que reinava desde o classicismo. Pouco a pouco se delineia o perfil do moderno diretor teatral [...] (TORRES NETO, 2001b, p. 273-274)

Não fosse assim, talvez os primeiros atores ou mesmo os próprios autores teriam acumulado, como foi o caso em algumas circunstâncias, a tarefa de ensaiar. Mas a atividade acabou se transformando em uma importante especialização, exercida em geral por ex-atores ou, mais raramente, ex-atrizes.

Se o advento do naturalismo marcou o surgimento do diretor moderno, com artistas como André Antoine, Firmin Germier ou Constantin Stanislavski, o do ensaiador propriamente dito pode ser identificado por volta da década de 1820. É a partir do movimento romântico, com sua preocupação com a "cor local', com as especificidades históricas e culturais, a valorização de costumes, a busca de uma "verdade" maior, enfim, que o ensaiador passou a ser 0 encarregado de garantir esse ambiente composto de tantos elementos: presença dos atores (movimento, dicção, expressividade), composição cenográfica, figurinos (históricos a princípio, contemporâneos posteriormente) social e culturalmente adequados, iluminação e sobretudo a correta interpretação das intenções do autor do texto. Não é por menos que, como aponta Filomena Chiaradia (1999) em seus estudos sobre a Companhia do Teatro São José de 
Paschoal Segreto, no Rio de Janeiro, no início do século xx, alguns autores, além de sempre acompanharem de perto o trabalho do ensaiador da companhia, acabaram por se tornar ensaiadores.

Elemento central no complexo cênico das companhias teatrais, pequenas ou grandes, o ensaiador era, portanto, mais do que um mero "guarda de trânsito". Dele se esperava a organicidade artística do espetáculo, o bom encaminhamento do desempenho dos atores, a adequação de cenários e figurinos e a solução dos problemas estéticos postos em cena.

Cabia ainda aos ensaiadores, ao que tudo indica, junto com o empresário e/ou o primeiro ator, a escolha do repertório que daria identidade ao grupo teatral. Em certos casos, as funções de ensaiador e empresário também se confundiam.

Por isso, é necessário que pesquisas voltadas especificamente para as atividades desse profissional e o estudo de casos nos levem a compreender melhor o papel exercido pelos ensaiadores no teatro brasileiro e sua transformação ao longo dos anos. É interessante observar que muitos (talvez a maioria) dos profissionais que atuaram no teatro nacional não eram brasileiros. Maria Helena Werneck, em estudo sobre a presença da ensaiadora/diretora ${ }^{6}$ portuguesa Esther Leão no Brasil, aponta:

Se considerarmos apenas os séculos XIX e XX, é possível acompanhar o longo convívio de atores brasileiros com artistas de teatro portugueses, através de percursos que começam com a Companhia de Mariana Torres, especialmente convidada para a abertura do Teatro São João, em 1813 , e tem continuidade depois de muitos outros eventos com a atuação de ensaiadores respeitados como Eduardo Vieira e Eduardo Victorino, nas primeiras décadas do século xx. Delineavam-se duas tradições complementares de formação de atores brasileiros forjadas no aprender vendo fazer o ator português e na mão firme do ensaiador. [...] Jayme Costa e Eva Tudor, que não dispensavam a experiência de "levantar um espetáculo" dos ensaiadores vindos de Portugal. (WERNECK, 2006, p. 228)

6. Durante muito tempo, os mesmos profissionais foram chamados de ensaiadores ou diretores de cena, ou ainda diretor artístico, indiferentemente. Por outro lado, às vezes, eles se apresentam como ensaiadores e diretores artísticos do mesmo espetáculo, o que mostra que eram atividades diferentes. As denominações não parecem ter sido muito rígidas e ainda estão para ser mais bem compreendidas. 
Assim, gostaria de apresentar três casos e começar a apontar similitudes e diferenças entre eles. Trata-se do francês Emile Doux (1798-1876), do italiano Enrico Cuneo e do português Eduardo Victorino (1869-1949).

Emile Doux, ou Emílio como ficou conhecido no Brasil, formou-se no Conservatório de Paris e, em 1834, partiu em turnê para Lisboa como ator e ensaiador na companhia teatral de M. Paul e mme. Charton. A companhia apresentou dramas românticos de Victor Hugo e Alexandre Dumas, comédias de Scribe, melodramas e vaudevilles. Quando partiu em 1837, Doux decidiu permanecer em Portugal, contratar atores portugueses e traduzir o repertorio anteriormente apresentado em francês. Foi Doux quem fixou o repertório romântico em Portugal, trazendo, enquanto ensaiador e diretor de cena ${ }^{7}$, uma nova forma de interpretação, mais natural, e de encenação, a partir de um

[...] rigor inquebrantável uma ciência profunda do teatro, preparou, formou e transformou com uma experiência lúcida e segura o grupo artístico nessa época. [...] Porque ensaiar não é somente movimentar as peças e espalhar a mobília pela cena... não. É adivinhar entre as linhas o que o autor não escreveu. É criar a personagem com vida própria ${ }^{8}$. (SIMÕES, 1922, p. 21)

Foi, aliás, de Emile Doux a encenação do drama de Almeida Garrett, Um auto de Gil Vicente, que inaugurou o teatro romântico português em 1838. Portanto, sua presença esteve no centro das atividades de renovação e modernização do teatro lusitano. Não fosse apenas essa a importância de Doux em Lisboa, ele ainda foi empresário e empreendedor tendo arrendado diversos teatros (Teatro dos Condes, Teatro do Salitre, Teatro do Ginásio e Teatro D. Fernando) para as várias trupes que comandou até sua partida para o Brasil em 1851.

No Rio de Janeiro, Doux juntou-se ao grupo de João Caetano dos Santos, maior ator brasileiro do período, trabalhando como "administrador fiscal", "administrador"9 e ensaiador de atores. Segundo Souza Bastos, Doux

7. Novamente a menção de duas atividades paralelas.

8. Depoimento da atriz portuguesa Lucinda Simões.

9. Qualificações que aparecem nos pedidos de liberação de peças à censura do Conservatório Dramático Brasileiro. 
[...] esforçou-se por renovar o repertorio do São Pedro, chegando mesmo a representar alguns vaudevilles [...] falava-se desta preferência por um repertório francês e atribuía-se isto ao fato de ser o ensaiador [...] um francês. (BASTOS, 2002, p. 65)

Pouco depois, Doux aparece nos registros do conservatório como "diretor de cena" e "ensaiador" do Teatro Ginásio Dramático, grupo rival ao de João Caetano e responsável pelo estabelecimento dos procedimentos realistas no teatro carioca. Foi Doux o responsável pela primeira temporada que apresentou no ginásio Um erro, de Scribe, e O primo da Califórnia, de Manuel de Macedo, e abriu o período realista da história do teatro brasileiro. José de Alencar veio saudar Doux:

[...] deu-nos as melhore esperanças, a representação correu bem em geral, e em algumas ocasiões excelente. [...] que os esforços do Sr. Emilio Doux sejam animados, que sua empresa alcance a proteção de que carece. (ALENCAR,1977, p. 66).

Aos elogios e incentivos de Alencar, vieram juntar-se aqueles de Machado de Assis, que teve algumas de suas comédias ensaiadas por ele:

A direção do Ateneu Dramático fez há tempos uma excelente aquisição. Para dar começo ao ensino prático que faz a base de seu programa, convidou o Sr. Emilio Doux que vai ensinar aos artistas ali contratados os preceitos da arte. (apud FARIA, 2008, p. 293)

Artista de grande experiência que transferira da França para Portugal e finalmente para o Brasil seu savoir faire, Doux também participou de outra iniciativa que visava colocar a cena nacional no compasso das praças mais modernas. No início da década de 1860, o ensaiador passou a trabalhar na Companhia de Ópera Nacional, fundada em 1858 para dar início ao teatro lírico brasileiro. Os melhores autores nacionais escreveram libretos para a nova formação. Em 1862, Doux ensaiou, por exemplo, Dous amores, um drama lírico em três atos.

Como se pode entrever, Emile Doux esteve envolvido em vários dos momentos mais significativos da história teatral portuguesa e brasileira (ou, pelo menos, lisboeta e carioca), tendo tido nelas participação ativa e até de- 
terminante. Entender as relações entre esses vários episódios da carreira de Doux pode contribuir para compreender melhor a trajetória desses teatros no século $\mathrm{XIX}^{10}$.

Outro ex-ator cuja atividade como ensaiador foi relevante, embora de muito menor expressão do que as de Emile Doux, foi o italiano Enrico Cuneo. $\mathrm{Na}$ verdade, sua contribuição foi bastante pontual, mas com desdobramentos interessantes.

Assim como Doux, Cuneo não foi um ator de talento excepcional, e é possível encontrar críticas pouco elogiosas sobre sua atuação. Por outro lado, como Doux, Cuneo ${ }^{11}$ trouxe novidades ao público brasileiro. No seu caso, tratou-se da obra de Shakespeare. Apresentada a partir das versões italianas encenadas por diversas companhias em turnês pelo Brasil e São Paulo a partir do final do século XIX, Shakespeare, assim como na Europa, se tornou cada vez mais popular pelas interpretações das tragédias mais famosas por atores italianos.

Porém, ao contrário de Doux, Cuneo não teve formação teatral escolar. Formou-se a partir dos grupos amadores e depois passou para os conjuntos profissionais, nos quais se especializou em autores franceses como Sardou e Dumas Filho. Veio ao Brasil pela primeira vez em 1894 com a Companhia Modena, da qual era o protagonista e ensaiador, e que entre os dramas e dramalhões franceses apresentava as tragédias inglesas. Os textos shakespearianos não eram encenados na versão integral e original, eram falados em italiano e geralmente tinham cenas cortadas e personagens e tramas paralelas ${ }^{12}$.

Cuneo voltou a São Paulo em outras ocasiões, com companhias de outros empresários e com a sua própria, ao lado de Zaíra Tiozzo. Em São Paulo, em 1897, apresentou Hamlet, Otelo e Romeu e Julieta no Teatro Politeama. A críti-

10. A autora está dando início a uma pesquisa de pós-doutorado sobre as atividades de Emile Doux na França e no Brasil.

11. Ao lado de outros atores italianos como Ernesto Rossi, Claudio Rossi, Ermete Novelli, Gustavo Salvini, Clara Della Guardia, Eleonora Duse e Giovani Emanuel, por exemplo. Houve também montagens não italianas, mas em número muito menor. No que diz respeito ao teatro em São Paulo, das 24 temporadas shakespearianas (até 1937), 18 foram de companhias italianas, duas francesas, duas portuguesas e duas alemãs.

12.É possível analisar as mudanças do texto a partir de roteiro em português que a companhia distribuía para que o público pudesse acompanhar o espetáculo. Alguns deles foram publicados nos jornais locais. 
ca, que já conhecia os trabalhos dos principais atores, não entrou em detalhes sobre seu desempenho, limitando-se a dizer que foram bastante aplaudidos.

Pouco tempo depois, Cuneo abandonou a companhia e se estabeleceu como comerciante no interior do estado de São Paulo. Contudo, seu papel no teatro paulista ainda não tinha terminado. Anos mais tarde, o vemos de volta à capital ensaiando um grupo de atores amadores em montagens das peças shakespearianas.

Como se sabe, o movimento amador paulistano, sobretudo de italianos e portugueses, era muito ativo no final do século XIX e no início do xx, com mais de cem grupos. Entre eles, o Teatro Popolare chegou a ter sede própria no bairro popular do Brás, na Rua do Gasômetro. Entre 1903 e 1904, o grupo reapresentou o mesmo repertório da antiga companhia de Cuneo, inclusive as peças de Shakespeare ${ }^{13}$ Hamlet, Romeu e Julieta e Otelo. Nesse agrupamento, Cuneo acumulava as funções de protagonista e "diretor".

As montagens do Teatro Popolare ganham nova dimensão quando se sabe que entre os membros do grupo estavam as irmãs Poloni, Carmela e Faustina. Faustina Poloni era o nome de batismo de Itália Fausta, que viria a ser uma das mais importantes atrizes de seu tempo, e com a irmã Carmela tinha iniciado sua vida artística nos grupos amadores da cidade ${ }^{14}$. Sempre elogiada, sabe-se que nas montagens de Hamlet fez o papel de Gertrude, enquanto sua irmã fez Ofélia. Essas foram as primeiras montagens shakespearianas paulistas de que se tem notícia.

O mais interessante de toda a atuação de Cuneo como ensaiador, ou diretor, dos amadores é que anos mais tarde, em 1938, Itália Fausta seria responsável pela histórica montagem de Romeu e Julieta do Teatro do Estudante do Brasil no Rio de Janeiro, um dos marcos do teatro brasileiro. Ela atuou como "diretora" da montagem brasileira.

Pode-se dizer então que as encenações do ensaiador italiano no Brasil no início do século foram um apoio, uma referência, uma ponte entre as montagens europeias apresentadas pelas companhias italianas e a primeira

13. Em 1903, Cuneo tinha montado um Hamlet no Teatro Santana sem saber ao certo quem compunha o restante da companhia, profissionais ou amadores. Tudo leva a crer que fossem amadores, uma vez que no ano seguinte uma companhia amadora já estava organizada, montando diversas peças.

14. Não só italianos, mas também dos portugueses como o Grêmio Dramático Luso-brasileiro. 
encenação brasileira da obra de Shakespeare. Novamente, por meio do ensaiador se estabelece a circulação de ideias e práticas entre diversas áreas da Europa e das Américas.

Por fim, deve-se atentar para a trajetória do ensaiador português Eduardo Victorino, que teve importante papel no teatro brasileiro do início do século xx. Mais conhecido que os outros dois já mencionados, atuou no limite temporal da passagem, pelo menos na Europa, entre a prática dos ensaiadores para o surgimento dos diretores.

Novamente, vê-se o esforço do ensaiador em renovar a cena nacional ao se declarar um seguidor do diretor André Antoine, que vinha modernizando a cena francesa. Victorino acreditava que a cena deveria buscar o máximo do realismo e que o teatro brasileiro deveria trilhar tal caminho. Para expor seu ponto de vista, escreveu em 1922 um raro balanço sobre a história do teatro brasileiro que não traça a trajetória da literatura dramática, mas a das práticas da cena sobre cenógrafos, maquinistas e, claro, ensaiadores. Para ele, a fraqueza do teatro nacional estava na dramaturgia ainda presa aos antigos modelos:

[...] tragam para cena os homens de hoje - homens, bem entendido, e não títeres como se veem nas comédias ligeiras que por aí se representam -e, não o duvidamos, os intérpretes aparecerão. (VICTORINO, 1922, p. 94)

É interessante a avaliação que faz da encenação no país. Segundo Victorino, ao contrário do que se poderia se supor, "no Brasil, o teatro, na mecânica e na arte da encenação, jamais esteve consideravelmente distanciado dos teatros mais adiantados do velho mundo" (VICTORINO, 1922, p. 95). Como responsáveis pelo bom desempenho da cena nacional, Victorino começa listando os mais antigos ensaiadores, Furtado Coelho e Emile Doux:

[...] qual deles o mais completo ensaiador, introduziram nos seus espetáculos todos os aperfeiçoamentos nos cenários, prestaram cuidados especiais ao mobiliário, conduziram os artistas a trajar com propriedade e elegância, e tiraram a representação, a ênfase e o cunho melodramático, imprimindo-lhe uma expressão mais natural. (VICTORINO, 1922, p. 96)

Em uma geração posterior, destacava os ensaiadores portugueses Dias 
Braga, Adolfo de Faria ${ }^{15}$ e Jacinto Heller. Portanto, é na tradição desses ensaiadores que Victorino se inclui, acreditando que a encenação deveria se aprimorar ainda mais na busca da verdade, fidelidade, precisão e exatidão. Para ele, Antoine e Firmin Gemier,

[...] com uma ciência absoluta, modificaram de alto a baixo essa arte tão complexa que eu, sócio e ensaiador da Companhia do inesquecível ator Dias Braga, meti ombros à tarefa de remodelar a encenação entre nós. (VICTORINO, 1922, p. 94)

Desse modo, nota-se que a contribuição de diversos ensaiadores estrangeiros radicados no Brasil, seja na corte ou em São Paulo, trouxe sensíveis modificações na realidade da cena nacional e que o estudo mais detalhado de suas atividades, relações, escolhas e técnicas poderia esclarecer melhor, por exemplo, a própria natureza de suas atividades. Veja-se, por exemplo, a questão da imprecisão da terminologia e nossa falta de compreensão da diversidade de tarefas. Podemos considerar como correspondentes os termos ensaiador e diretor de cena? Ou diretor artístico e fiscal de cena no contexto do teatro do século xIx e início do xx? Seriam essas variações da tradução do termo francês "metteur-em-scène" ou seria necessário considerar o termo "régisseur", como sugere Eugénia Vasques?

O quanto o ensaiador era responsável ou corresponsável pela escolha do repertório das companhias? Como a presença desses ensaiadores estrangeiros contribuiu para o trânsito de ideias e práticas entre o teatro europeu $\mathrm{e}$ o brasileiro? Estas são questões que ainda esperam respostas.

\section{Referências bibliográficas}

AZEVEDO, E. R. Emil(e)io Doux trajetória de um ensaiador francês em direção aos trópicos. In: WERNECK, M. H.; REIS, Â. C. Rotas de teatro entre Portugal e Brasil. Rio de Janeiro: 7Letras, 2012. p. 33-58.

. Um Shakespeare ítalo-paulista. Pitágoras 500, Campinas, v. 7, p. 21-41, dez. 2014.

BALME, C. Histórias globais do teatro: modernização, esfera pública e redes teatrais transnacionais. In: WERNECK, M. H.; REIS, Â. de C. Rotas de teatro entre Portugal e Brasil. Rio de Janeiro: 7Letras, 2012. p. 203-219.

15. Adolfo de Faria nasceu no Brasil, mas se formou em Portugal. 
CHARLE, C. A gênese da sociedade do espetáculo. São Paulo: Companhia das Letras, 2012.

CHIARADIA, F. Cardoso de Menezes e Carlos Bittencourt no teatro São José: autores-ensaiadores do teatro ligeiro. Folhetim, Rio de Janeiro, n. 4, p. 40-51, 1999.

DAMASCENO, A. Palco, salão e picadeiro em Porto Alegre no século xix: contribuição para o estudo do processo cultural do Rio Grande do Sul. Rio de Janeiro: Globo, 1956.

FARIA, J. R. (Org.). Machado de Assis: do teatro (textos críticos e escritos diversos). São Paulo: Perspectiva, 2008.

Os ensaiadores, os intérpretes e o espetáculo teatral realista. In:

(Org.). História do Teatro no Brasil I: das origens ao teatro profissional da primeira metade do século xx. São Paulo: Perspectiva; SESC-SP, 2012. p. 185-200.

FERNANDES, S. Nota sobre Victorino. Revista Sala Preta, São Paulo, n. 3, p. 174180, 2003.

RAMOS, L. F. A arte do ator e o espetáculo teatral. In: FARIA, J. R. (Org.). História do Teatro no Brasil I: das origens ao teatro profissional da primeira metade do século xx. São Paulo: Perspectiva; SESC-SP, 2012. p. 137-158.

SIMÕES, L. Memórias, factos e impressões. Rio de Janeiro: Litho-Typographia Fluminense, 1922.

TORRES NETO, W. L. Entre técnica e arte: trabalho teatral do ensaiador na virada do século XIX/XX. Anais do II Congresso Brasileiro de Pesquisa em Pós-Graduação em Artes Cênicas. Salvador: UFBA-ABRACE, 2001a. p. 272-278.

Introdução histórica: o ensaiador, o diretor e o encenador. Folhetim, Rio de Janeiro, n. 9, p. 60-71, 2001b.

Entre técnica e arte: introdução à prática teatral do ensaiador, 1890-1954.

Revista Sala Preta, São Paulo, n. 3, p. 164-173, 2003.

Breve introdução ao teatro europeu do pós-guerra. In: GOMES, A. L.; MACIEL,

D. A. V. Dramaturgia e teatro: intersecções. Maceió: EDUFAL, 2008. p. 269-290.

VASQUES, E. Para a história da encenação em Portugal: o difícil progresso do conceito de encenação no teatro (1837-1928). Lisboa: Sá da Costa, 2010.

VICTORINO, E. Cem anos de teatro. A mecânica teatral e a arte de encenação. Illustração Brasileira, Rio de Janeiro, ano III, n. 28, dez. 1922, p. 94-96.

WERNECK, M. H. Entre mares e palcos: notas sobre Esther Leão (1892-1971), uma portuguesa no teatro brasileiro. In: MALUF, S. D.; AQUINO, R. B. Dramaturgia em cena. Maceió: EDUFAL, 2006. p. 227-242.

Recebido em 16/05/2015

Aprovado em 23/05/2015

Publicado em 30/06/2015

Revista sala preta | Vol. 15 | n. 1 | 2015 